\title{
Statistical study of wind speed variations by Weibull parameters for Socotra Island, Yemen
}

\author{
Saif Sera ${ }^{1, *}$, Khalid Ibaaz $^{2}$, and Adil Echchelh ${ }^{1}$ \\ ${ }^{1}$ Laboratory of Energetic Engineering and Materials, Ibn Tofail University, Kenitra, Morocco \\ ${ }^{2}$ Engineering for Smart and Sustainable Systems Research Center, Mohammadia School of Engineers, Mohamed V University in Rabat, \\ Morocco
}

\begin{abstract}
According to the International Energy Agency (IEA-2013), Electricity alone does not create all the conditions for socioeconomic growth, but it is obviously essential to meet basic human needs and facilitate the development of economic activities. For the isolated areas with high wind potential and the island suffering from the electrification problems, the prospective solution is the use of renewable energies, especially wind energy. The present paper deals with a detailed statistical study on wind energy, its parameters, and variables on Socotra Island in Yemen, where that island is isolated from the main electricity grid in addition to the difficulty of providing electrical energy to this region in light of conditions in which Yemen has been living in recent times. The simulation results prove that the mean wind speed can reach a value ranging from 8.36 to $10.36 \mathrm{~m} / \mathrm{s}$, which is a large and enough speed to generate electricity using turbine farms. Based on the $\mathrm{k}$ and $\mathrm{c}$ Weibull parameters, the maximum probability at speeds 3 and $4 \mathrm{~m} / \mathrm{s}$ is 0,052 , while a value of 0,085 at speed $7 \mathrm{~m} / \mathrm{s}$ is given by Rayleight distribution. Every result proved that Yemen has a good wind energy potential can utilize it for electrical energy production, and that strengthens the planning of economical wind turbines capacity for electricity production in the region.
\end{abstract}

\section{Introduction}

The energy revolution nowadays is recommended at all scales of life. It became a major element of sustainable development. To keep up this revolution, many countries have opted for strategies to stop using fossil fuels and achieve environmental goals [1]. The use of renewable energies is being widely encouraged for its dominance to achieve near-zero emissions and to remedy environmental problems. Among renewable energies that have gained significant public support and appear to be the most commercially viable method; wind energy, the most widely implemented renewable energies [2 - 3]. Wind energy can meet the large need of energy for any places, whether near or direct, grid-connected or far as well as grid- isolated [4 - 5]. Because of the negative impact on the environment and the high cost of using conventional energy sources, the exploitation of wind energy in electric power systems is growing rapidly [5].

The study of wind speed data, characteristics, and analysis of this data are very important to assess the potential of wind speed in any location for study the ability to produce electrical energy by wind turbines [ 6 7]. The study of wind speed according to the surface terrain comes in two types, the first is onshore wind, which indicates the installation of turbines on land, and the second type concern offshore wind, its refers to installations that are installed in water bodies. The first type is most used and has proven a great success for energy production, however recently, offshore winds have become more preferred due stability of wind resources, less noise because installed far from residential neighborhoods, fewer restrictions on the size of turbines, and less impact on the environment [8 - 9].

There has been significant research on the development and utilization of renewable energies in Yemen. Due to their abundance, they can provide complete security of energy supply through favorable exploitation. However, the use of renewable energy sources remained individual, indiscriminate and is not sufficient to generate electricity for a long and arranged period as solar or wind turbine stations provide. Regarding the wind energy in Yemen, many works have been done in order to investigate its potential in many cities. Due to its technologies development among the renewable energy technologies, the wind energy has the advantage of being the suitable source for the area like Yemen [10 - 11].

The rest of this paper is organized as follows. Section I presents the site of study which is Socotra Archipelago and its data. Section II depicts the methodology. The

*Corresponding author: saifserag75@gmail.com 
results are given and discussed in Section III. Finally, the conclusion is presented in Section IV.

\section{Study location}

The study site is the Socotra Archipelago. Considered as the largest island of the Yemen islands with an area of $3650 \mathrm{Km} 2$, the island is located in the Arabian Sea. 380 $\mathrm{km}$ (238 miles) south of mainland Yemen and $80 \mathrm{~km}$ west of the Horn of Africa.[12].It is located between two latitudes (12.18 - 12.24) North of the equator and longitudes (53.19-54.33) East of Greenwich. Socotra archipelago includes many small islands located in the western side, including a " Socotra,Abdu Alkuri, Samhah, Arsah, Siyal, Siyal Socotra "[13].

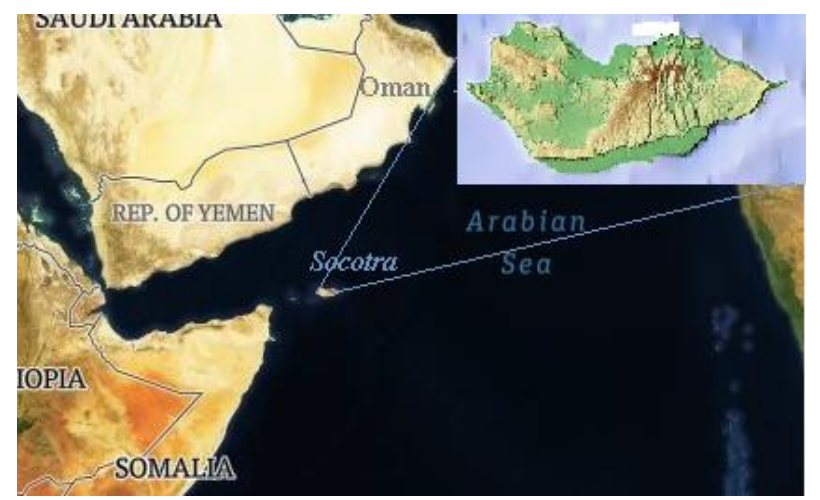

Fig. 1. Socotra Island location

Data contained in this research were obtained from two sources, the first one is the General Authority of Meteorology in Yemen, and we have obtained mean wind speed values from 2006 to 2010 . The second source is via infoclimat [14], where This site displays the wind speed for every year, every month, day and hour, as this site has provided wind speed to 2014, which is the last year before the fall of the Yemeni government at the beginning of 2015. In this article, we will show the average wind speeds from 2006 to 2014 , and we will study in detail the speeds, parameters, and wind speed variables of year 2014 as an optional data to study the variables of Socotra Island.

\section{Methodology}

To study the possibility of generating energy, and it economic feasibility for any location easily, we must study the distribution of wind speed, its frequencies and directions for that region by studying distribution function and energy density, and these methods will be presented in detail for applying it to analyze wind speed data in study area.

\subsection{Weibull distribution function}

The first fundamental step to assess the wind energy potential is the estimation of the wind speed probability distribution function (PDF). In other words, the wind speed probability distribution function allows to determine the performance of wind energy systems for a given location. For the case study, the Weibull Probability Density Function, one of the PDFs, have been selected due to its accurate and adequate estimation of wind energy potential as well as its analysis and interpretation of the wind speed distribution.

Weibull parameters are expressed by shape parameter $\mathrm{k}$ and scale parameter $\mathrm{c}(\mathrm{m} / \mathrm{s})$, which are the most important parameters that enable us to calculate the probability density function $\mathrm{f}(\mathrm{v})$ and cumulative distribution function $\mathrm{F}(\mathrm{v})$ of wind speeds, which can be expressed by Eqs (1),(2) [15][16]:

$$
\begin{gathered}
f(v)=\frac{k}{c}\left(\frac{v}{c}\right)^{k-1} \times \exp \left[-\left(\frac{v}{c}\right)^{k}\right] \\
F(v)=1-\exp \left[-\left(\frac{v}{c}\right)^{k}\right] .
\end{gathered}
$$

Where $\mathrm{v}$ is the wind speed.

Weibull parameters are calculated by standard deviation $\sigma$, which is given by the flowing equation (3) [16][18]:

$$
\sigma=\sqrt{\frac{1}{n-1} \sum_{i=1}^{n}\left(v_{i}-v_{m}\right)^{2}}
$$

$\mathrm{k}$ and $\mathrm{c}$ are calculated by equations (4) and (5):

$$
\begin{aligned}
& k=\left(\frac{\sigma}{v_{m}}\right)^{-(1.086)} . \\
& c=\left(\frac{v_{m}}{\Gamma\left(1+\frac{1}{k}\right)}\right) .
\end{aligned}
$$

Where $v_{m}$ is the mean wind speed calculated by (6):

$$
v_{m}=\frac{1}{n}\left(\sum_{i=1}^{n} v_{i}\right) \text {. }
$$

The gamma function is expressed by the equation (7) if $\mathrm{y}=(1+1 / \mathrm{k})$ :

$$
\Gamma(y)=\int_{0}^{\infty} \exp (-x) x^{y-1} d x
$$

\subsection{Rayleigh distribution}

Rayleigh distribution is a special case of Weibull distribution. The probability density and the cumulative function can be calculated according to Rayleigh distribution by Eqs (8) and (9), where, they change according to speed $\mathrm{v}$ and mean speed $\mathrm{vm}$ values of wind:

$$
\begin{aligned}
& f_{r}(v)=\frac{\pi v}{2 v_{m}^{2}} \exp \left[-\left(\frac{\pi}{4}\right)\left(\frac{v}{v_{m}}\right)^{2}\right] \\
& F_{R}(v)=1-\exp \left[-\left(\frac{\pi}{4}\right)\left(\frac{v}{v_{m}}\right)^{2}\right]
\end{aligned}
$$

\subsection{Wind power density}

Wind power can be calculated using the equation (10) [16]: 


$$
p_{(v)}=\frac{1}{2} \rho A v_{m}^{3}
$$

The wind power density based on the mean wind speed, density function are given by equations (11) (12) [18]:

$$
\begin{gathered}
\frac{p_{(v)}}{A}=\frac{1}{2} \rho v_{m}^{3} . \\
\frac{p_{(v)}}{A}=\frac{1}{2} \rho c^{3} \Gamma\left(1+\frac{3}{k}\right) .
\end{gathered}
$$

Also, we can calculate most probable wind speed ( $\left.\mathrm{V}_{\mathrm{MP}}\right)$ and most energy $\left(\mathrm{V}_{\mathrm{MaxE}}\right)$ from wind speed [17] :

$$
\begin{gathered}
V_{m p}=c\left(\frac{k-1}{k}\right)^{\frac{1}{k}} . \\
V_{\text {MaxE }}=c\left(\frac{k+2}{k}\right)^{\frac{1}{k}} .
\end{gathered}
$$

\subsection{Variation of wind speed with height}

It is necessary to study wind speed changes, with counting different heights, since most wind speed data are taken at a specific height, and most of the economic benefits are made at greater heights than that and mimic the turbine tower heights[17]. The model for that is Yemen Meteorological Authority, as it takes wind speed data at a distance of 10 meters. Wind speed can be measured according to the change in altitude according to the equation (14).

$$
v=v_{0}\left(\frac{h}{h_{0}}\right)^{\alpha} .
$$

where v0 wind speed at the original height of meteorological observatory (h0), $\mathrm{v}$ wind speed which wants to measure at height (h), $\alpha$ wind shear value depends on surfaceroughness and is estimated at 0.14 [15].

\section{Results and discussion}

\subsection{Wind speed data}

Based on available data from 2006 to 2014 (fig. 2), Socotra has mean wind speeds between $8.36-10.36 \mathrm{~m} / \mathrm{s}$. the maximum value was registered in 2010 while the minimum value in 2007.

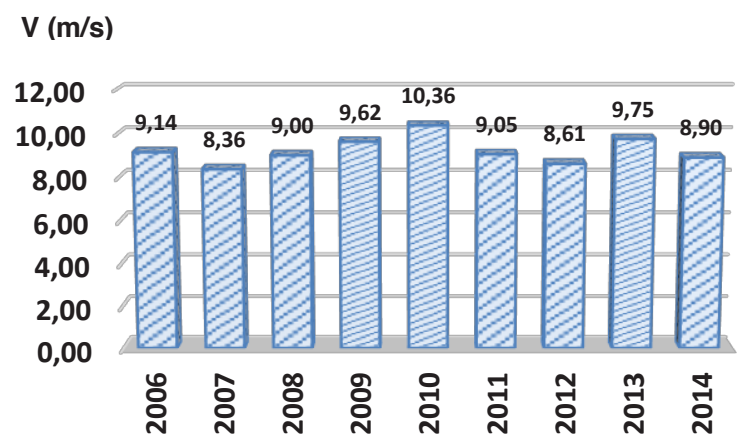

Fig. 2. Mean of wind speed 2006-2014
Figure 3 shows the monthly variation of wind speed for the year of 2014. It's clear that the wind speed increase from the beginning of June and continue to increase until it reaches its maximum value in July, after this period it decrease in August and September. Low values of wind speed occur during February, March, April, October and November, while January and December have mean values for wind speed.

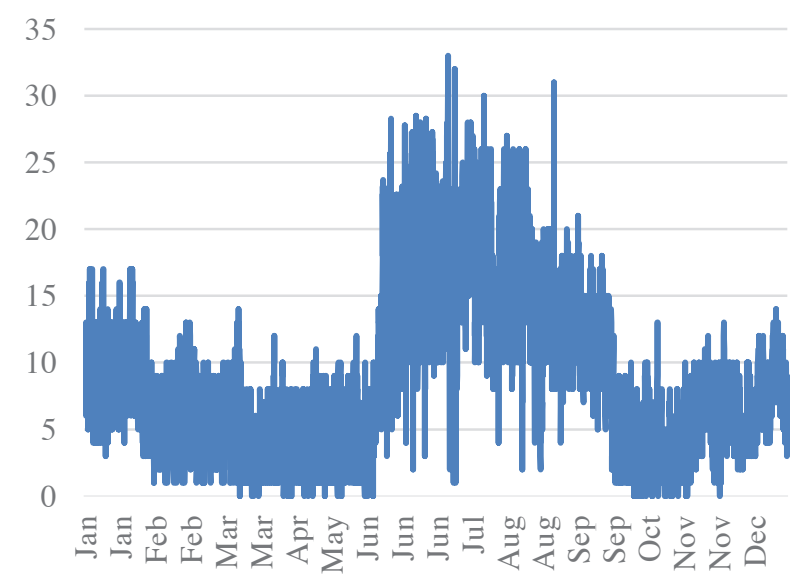

Fig. 3. Wind Speed 1 year (2014)

\subsection{Weibull and Rayleigh distribution}

The study of Weibull and Rayleigh distribution will be applied to 2014 in detail, these values will be calculated to estimate wind distribution for each month of this year. Figure (3) shows details of wind speed per hour throughout 2014, where it appears that the maximum value of wind speed reached $33 \mathrm{~m} / \mathrm{s}$, it is normal for the minimum value to be zero, as it is reported in March, April, May, October, and November. The year 2014 has an average monthly wind speed between 3.6 (October) to 18.38 (July) $\mathrm{m} / \mathrm{s}$. Table (1) summarizes the mean wind speeds for each month, as well as the values of standard deviation, which allows studying variation of wind speed between value of speed and mean speed. Table (1) also contains values of $\mathrm{k}$ (Shape factor) and $\mathrm{c}$ (Scale parameter) calculated based on equations (4) and (5) respectively, these values depend on values of mean wind speed and standard deviation. The maximum calculated value of $\mathrm{c}$ is $20.15 \mathrm{~m} / \mathrm{s}$ for the month of July, while the lowest value is $4.1 \mathrm{~m} / \mathrm{s}$ for the month of April. It has been observed that wind speed frequencies on Socotra Island have great values at speeds between 3 and $8 \mathrm{~m} / \mathrm{s}$, the largest value is at $5 \mathrm{~m} / \mathrm{s}$ where its frequency reached 0.093, the frequency values decrease significantly until reaching a zero value for speeds ranging from 30 to 33 $\mathrm{m} / \mathrm{s}$. As for the probability density (Figure 4 ), the Weibull distribution maximum value equal to 0.052 at wind speed 3 and $4 \mathrm{~m} / \mathrm{s}$, and the minimum value corresponds to the speed of $0 \mathrm{~m} / \mathrm{s}$ and the speeds ranging from 25 to $33 \mathrm{~m} / \mathrm{s}$. Concerning the probability density according to Rayleigh distribution, the maximum value reached 0.085 at speed 7 $\mathrm{m} / \mathrm{s}$, while the lowest value is at zero and speeds ranging from 23 to $33 \mathrm{~m} / \mathrm{s}$. 
Table 1. Monthly Standard deviation and Weibull parameters in Socotra (2014)

\begin{tabular}{ccccccccccccc}
\hline Month & 1 & 2 & 3 & 4 & 5 & 6 & 7 & 8 & 9. & 10 & 11 & 12 \\
\hline $\mathrm{Vm}_{\mathrm{m}}$ & 7.46 & 6.12 & 5.10 & 3.70 & 4.35 & 14.60 & 18.38 & 15.62 & 11.34 & 3.60 & 5.90 & 7.13 \\
\hline$\sigma$ & 2.24 & 2.52 & 2.61 & 2.18 & 2.54 & 6.27 & 4.56 & 4.01 & 3.43 & 2.63 & 2.53 & 2.48 \\
\hline $\mathrm{k}$ & 3.69 & 2.61 & 2.06 & 1.78 & 1.86 & 2.5 & 4.54 & 4.37 & 3.65 & 1.57 & 2.48 & 3.14 \\
\hline $\mathrm{c}$ & 8.27 & 6.89 & 5.75 & 4.16 & 4.9 & 16.45 & 20.15 & 17.14 & 12.57 & 4.01 & 6.65 & 7.96 \\
\hline
\end{tabular}

Table 2. Monthly Most probable wind speed ( $\left.\mathrm{V}_{\mathrm{MP}}\right)$ and Most energy

\begin{tabular}{ccccccccccccc}
\hline Month & 1 & 2 & 3 & 4 & 5 & 6 & 7 & 8 & 9. & 10 & 11 & 12 \\
\hline $\mathrm{V}_{\mathrm{MP}}$ & 7.59 & 5.73 & 4.16 & 2.62 & 3.24 & 13.41 & 19.08 & 16.15 & 11.51 & 2.10 & 5.40 & 7.05 \\
\hline $\mathrm{V}_{\mathrm{MaxE}}$ & 9.30 & 8.57 & 7.99 & 6.35 & 7.26 & 20.81 & 21.84 & 18.68 & 14.17 & 6.77 & 8.44 & 9.31 \\
\hline
\end{tabular}

Moreover, cumulative function indicates the probability that a portion of time for wind speed is equal to or less than mean wind speed, and gives an estimate of the time when wind is within a certain speed interval. Figure 5 shows that the probability of wind speed blows at a mean speed $v_{m}$ is equal to one with speeds less than or equal to $28 \mathrm{~m} / \mathrm{s}$. Table 2 displays the most probable wind speed (VMP) and most energy (VMaxE) of monthly wind speed, based on parameters $\mathrm{k}$ and $\mathrm{c}$.

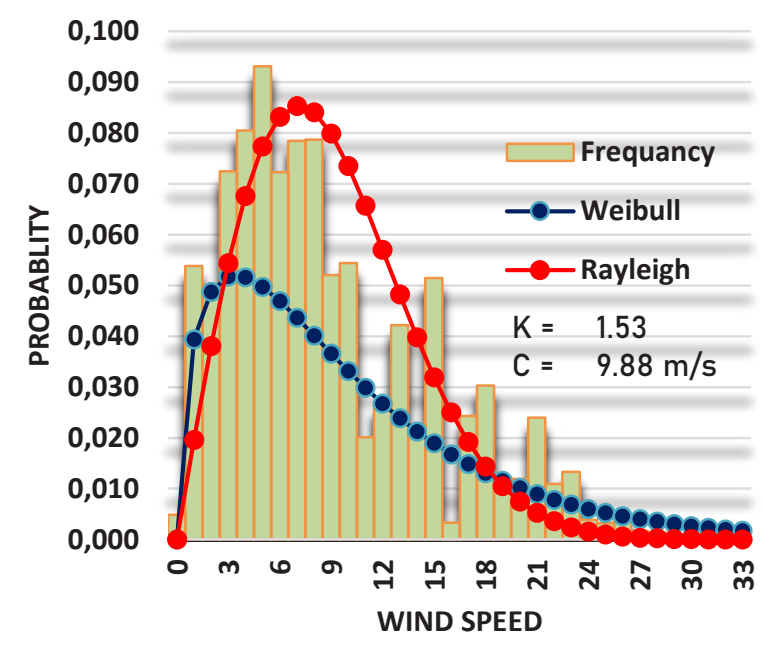

Fig. 4. Frequency, Weibull and Reyleigh probability density

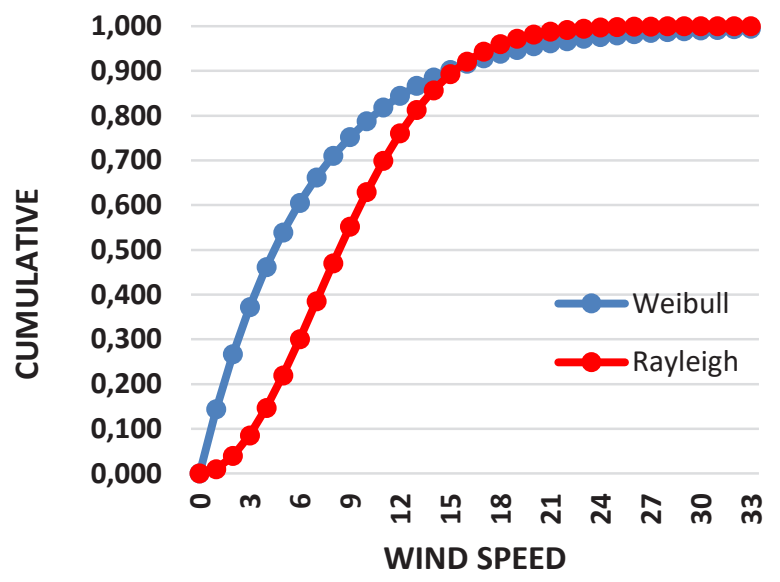

Fig. 5. Cumulative density distribution

\subsection{Wind directions}

It is necessary to study the wind directions in Socotra Archipelago in order to identify the appropriate method for installing wind farms, depending on directions and information's of wind speed. For that purpose, and for the site study, figure (6) showed the yearly wind speed directions of 2014. It is noticeable that the most wind directions are West and Southwest for January and February. As for March, April, May, October, November and December, they are Southwestern whereas June and July are in the Northeast. August was distinguished from other months by 3 directions of which 2 are confronting each other, Northeast and Southwest, and third one is South direction.

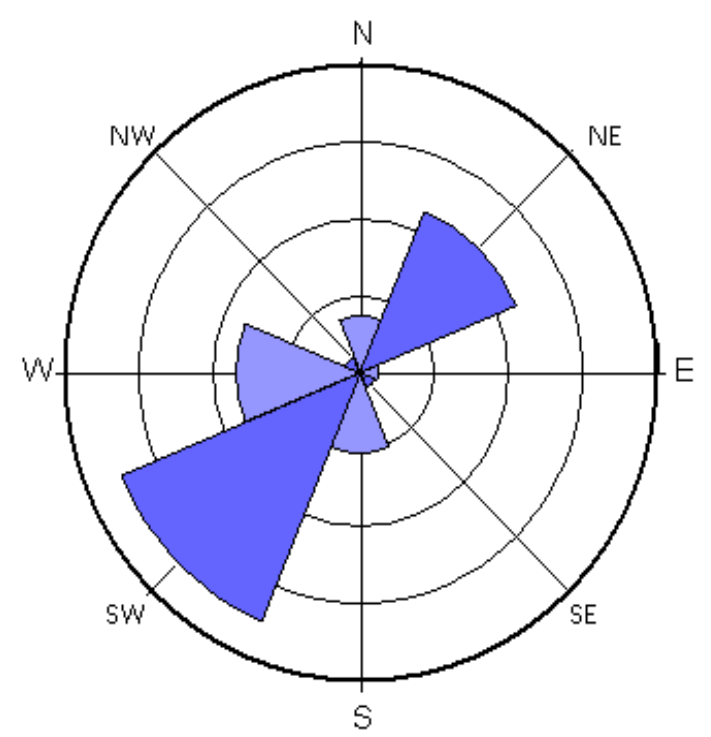

Fig. 6. Socotra wind directions for 2014

\subsection{Wind power density (WPD) and Wind Energy (WE)}

Table 3 shows Wind power density and Wind Energy that can be produced during each month of 2014. Since energy density is directly proportional to cubic wind speed, the largest value of mean wind speed will have largest value of wind power density and wind Energy. Notice that the Maximum value (July) of wind power density is equal to 
$3803.14 \mathrm{~W} / \mathrm{m} 2$ and the wind energy is equal to 2738.26 $\mathrm{kWh} / \mathrm{m} 2$, while minimum value (October) corresponds to $28.58 \mathrm{~W} / \mathrm{m} 2$, and wind energy is equal to $20.58 \mathrm{kWh} / \mathrm{m}^{2}$.

\subsection{Variation of wind speed with height}

According to the equation (15) which translates the variation of wind speed with height, wind speed increases by increasing height. Table 4 shows the values of the mean wind speed, standard deviation, Weibull parameters, wind power density (WPD) and Wind Energy (WE) calculated depending of height, first at $65 \mathrm{~m}$ and second at $100 \mathrm{~m}$. Figure (7) also presents variations of mean wind speed at a different height: 10,65 and $100 \mathrm{~m}$.

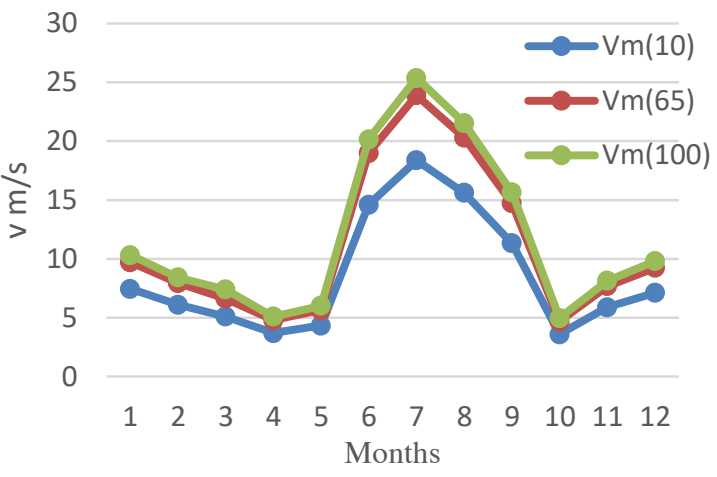

Figure. 7. Mean wind speed in different height

Table 3. Wind power density and Wind Energy Socotra (2014)

\begin{tabular}{ccccccccccccccc}
\hline Month & 1 & 2 & 3 & 4 & 5 & 6 & 7 & 8 & 9. & 10 & 11 & 12 \\
\hline $\mathrm{v}_{\mathrm{m}}$ & 7.46 & 6.12 & 5.10 & 3.70 & 4.35 & 14.60 & 18.38 & 15.62 & 11.34 & 3.60 & 5.90 & 7.13 \\
\hline $\mathrm{WPD}\left(\mathrm{W} / \mathrm{m}^{2}\right)$ & 254.29 & 140.40 & 81.25 & 31.02 & 50.42 & 1906.18 & 3803.14 & 2334.26 & 893.19 & 28.58 & 125.79 & 222.01 \\
\hline $\mathrm{WE}\left(\mathrm{kWh} / \mathrm{m}^{2}\right)$ & 183.09 & 101.09 & 58.50 & 22.34 & 36.30 & 1372.45 & 2738.26 & 1680.67 & 643.10 & 20.58 & 90.57 & 159.85 \\
\hline
\end{tabular}

Table 4. Variation at mean and parameters of wind speed according to different heights $65 \mathrm{~m}-100 \mathrm{~m}$

\begin{tabular}{c|c|cccccccccccc}
\hline Hight & Month & 1 & 2 & 3 & 4 & 5 & 6 & 7 & 8 & 9. & 10 & 11 & 12 \\
\hline \multirow{6}{*}{$65 \mathrm{~m}$} & $\mathrm{~V}_{\mathrm{m}}$ & 9.72 & 7.95 & 6.63 & 4.8 & 5.66 & 19 & 23.9 & 20.3 & 14.74 & 4.69 & 7.68 & 9.24 \\
& $\mathrm{k}$ & 3.59 & 2.48 & 2.07 & 1.79 & 1.87 & 2.57 & 4.51 & 4.3 & 3.7 & 1.59 & 2.47 & 3.03 \\
& $\mathrm{c}$ & 10.79 & 8.96 & 7.48 & 5.4 & 6.37 & 21.4 & 26.81 & 22.3 & 16.33 & 5.22 & 8.65 & 10.34 \\
& $\sigma$ & 2.99 & 3.44 & 3.38 & 2.8 & 3.17 & 7.95 & 5.96 & 5.2 & 4.4 & 3.05 & 3.33 & 3.32 \\
& $\mathrm{Vmp}$ & 9.852 & 7.276 & 5.438 & 3.419 & 4.231 & 17.67 & 25.36 & 20.97 & 15 & 2.798 & 7.011 & 9.06 \\
& $\mathrm{VmaxE}$ & 12.21 & 11.37 & 10.37 & 8.211 & 9.398 & 26.77 & 29.08 & 24.37 & 18.35 & 8.712 & 11 & 12.22 \\
\hline \multirow{6}{*}{$100 \mathrm{~m}$} & $\mathrm{Vm}$ & 10.32 & 8.44 & 7.4 & 5.1 & 6.02 & 20.16 & 25.36 & 21.54 & 15.65 & 4.98 & 8.15 & 9.81 \\
& $\mathrm{k}$ & 3.73 & 2.51 & 2.31 & 1.71 & 1.85 & 2.58 & 4.52 & 4.32 & 3.64 & 1.53 & 7.47 & 3.16 \\
& $\mathrm{c}$ & 11.43 & 9.51 & 7.94 & 5.72 & 6.77 & 22.7 & 27.78 & 23.65 & 17.35 & 5.53 & 9.18 & 10.95 \\
& $\sigma$ & 3.07 & 3.61 & 3.25 & 3.11 & 3.42 & 8.42 & 6.32 & 5.6 & 4.76 & 3.36 & 3.49 & 3.39 \\
& $\mathrm{Vmp}$ & 10.51 & 7.767 & 6.211 & 3.421 & 4.447 & 18.77 & 26.28 & 22.25 & 15.88 & 2.766 & 9.005 & 9.708 \\
& $\mathrm{VmaxE}$ & 12.82 & 12.01 & 10.4 & 8.997 & 10.06 & 28.36 & 30.13 & 25.83 & 19.57 & 9.551 & 9.476 & 12.79 \\
\hline
\end{tabular}

\section{Conclusion}

In this paper the wind speed data for Socotra Island were statically analyzed by investigating their mean wind speed frequencies, Weibull, and Rayleigh distribution. The wind energy potential of the location has been studied based on the Weibull model. Referring to the different graphs as well as the calculation tables, the most important results of the study can be concluded as follows:

$>$ Socotra has a mean wind speed between 8.36 to 10.36 $\mathrm{m} / \mathrm{s}$, which is a large and enough speed to generate electricity by using turbine farms.

$>$ the maximum probability based on the $\mathrm{k}$ and $\mathrm{c}$ Weibull parameters is 0.052 at speeds 3 and $4 \mathrm{~m} / \mathrm{s}$ while Rayleigh distribution gave maximum value of 0.085 at speed $7 \mathrm{~m} / \mathrm{s}$ and the largest probability of the frequency is 0.093 at Speed $5 \mathrm{~m} / \mathrm{s}$.

$>$ Most wind directions in Socotra are southwest to south, except June, July, and September, as their directions are northeast for most of their hours, and August is characterized by two opposite directions, which are northeast and southwest.

$>$ The values of wind speeds increase with height, and the study showed a noticeable increase in mean wind speed for year 2014, with an increase height from 10 $\mathrm{m}$ to $65 \mathrm{~m}$ and $100 \mathrm{~m}$.

\section{References}

1. M. Ucal and G. Xydis, 'Multidirectional Relationship between Energy Resources, Climate Changes and Sustainable Development: Technoeconomic Analysis', Sustain. Cities Soc., vol. 60, p. 102210, Sep. 2020, doi: 10.1016/j.scs.2020.102210.

2. D. Y. C. Leung and Y. Yang, 'Wind energy development and its environmental impact: A review', Renew. Sustain. Energy Rev., vol. 16, no. 1, pp. 1031-1039, Jan. 2012, doi: 10.1016/j.rser.2011.09.024.

3. D. Weisser, 'A wind energy analysis of Grenada: an estimation using the "Weibull" density function', Renew. Energy, vol. 28, no. 11, pp. 1803-1812, Sep. 2003 ,

4. V. R. Chowdhury and D. Kastha, 'Control of a Selfexcited Squirrel Cage Induction Machine based Wind 
Energy Conversion System Operating in Both Stand Alone and Grid Connected Modes', Energy Procedia, 2014.

5. M. Carolin Mabel and E. Fernandez, 'Growth and future trends of wind energy in India', Renew. Sustain. Energy Rev., vol. 12, no. 6, pp. 1745-1757, Aug. 2008, doi: 10.1016/j.rser.2007.01.016.

6. M. Shoaib, I. Siddiqui, S. Rehman, S. Khan, and L. M. Alhems, 'Assessment of wind energy potential using wind energy conversion system', J. Clean. Prod., vol. 216, pp. 346-360, Apr. 2019, doi: 10.1016/j.jclepro.2019.01.128.

7. E. Kavak Akpinar and S. Akpinar, 'A statistical analysis of wind speed data used in installation of wind energy conversion systems', Energy Convers. Manag., , Mar. 2005.

8. M. D. Esteban, J. J. Diez, J. S. López, and V. Negro, 'Why offshore wind energy?', Renew. Energy, vol. 36, no. 2, pp. 444-450, Feb. 2011, doi: 10.1016/j.renene.2010.07.009.

9. H. Díaz and C. Guedes Soares, 'Review of the current status, technology and future trends of offshore wind farms', Ocean Eng., Aug. 2020, doi: 10.1016/j.oceaneng.2020.107381.

10. A. G. Alkholidi, 'Renewable Energy Solution for Electrical Power Sector in Yemen', p. 9, 2013.

11. A. Q. Saleh Qasem, 'Applications of Renewable Energy in Yemen', J. Fundam. Renew. Energy Appl., vol. 08 , no. 02, 2018,
12. 'Socotra islands scenery in Yemen-China Youth International'. http://en.youth.cn/yculture/200911/ t20091118_1085530.htm (accessed Mar. 17, 2020).

13. F. Attorre, N. Taleb, M. De Sanctis, A. Farcomeni, A. Guillet, and M. Vitale, 'Developing conservation strategies for endemic tree species when faced with time and data constraints: Boswellia spp. on Socotra (Yemen)', Biodivers. Conserv., vol. 20, no. 7, pp. 1483-1499, Jun. 2011,.

14. 'Infoclimat - la météo en temps réel : observations météo en direct, prévisions, archives climatologiques, photos et vidéos...'https://www.infoclimat.fr/ (accessed Mar. 22, 2020).

15. M. Gökçek, A. Bayülken, and Ş. Bekdemir, 'Investigation of wind characteristics and wind energy potential in Kirklareli, Turkey', Renew. Energy, vol. 32, no. 10, pp. 1739-1752, Aug. 2007, doi: 10.1016/j.renene.2006.11.017.

16. O. S. Ohunakin and O. O. Akinnawonu, 'Assessment of wind energy potential and the economics of wind power generation in Jos, Plateau State, Nigeria', Energy Sustain. Dev., vol. 16, no. 1, pp. 78-83, Mar. 2012.

17. M. B. H. Kumar, S. Balasubramaniyan, S. Padmanaban, and J. B. Holm-Nielsen, 'Wind Energy Potential Assessment by Weibull Parameter Estimation Using Multiverse Optimization Method: A Case Study of Tirumala Region in India', Energies, vol. 12, no. 11, p. 2158, Jun. 2019 